\title{
O GOLPE DE 1964 NA ORDEM DO DIA: MEMÓRIA E SILENCIAMENTO NO PROCESSO DISCURSIVO DE LEGITIMAÇÃO DA VIOLÊNCIA DE ESTADO
}

\author{
THE 1964 COUP ON THE AGENDA: \\ MEMORY AND SILENCE IN THE DISCURSIVE PROCESS OF LEGITIMIZING \\ STATE VIOLENCE
}

\author{
DOI 10.20873/uft2179-3948.2021v12n1p25-48
}

\author{
Bethania Sampaio Corrêa Mariani ${ }^{1}$ \\ Milene Maciel Carlos Leite ${ }^{2}$ \\ Ariana da Rosa Silva ${ }^{3}$
}

\begin{abstract}
Resumo: Este artigo, filiado ao arcabouço teórico da Análise do Discurso materialista, considerando, especialmente, os conceitos de memória, silêncio, historicidade, propõe um gesto de análise de três documentos institucionais emitidos pelo Ministério da Defesa do atual governo nos anos de 2019, 2020 e 2021 que consistem na Ordem do Dia Alusiva ao 31 de Março de 1964. O principal objetivo é compreender de que modo essas notas oficiais de comemoração/rememoração do golpe de 1964 emitidas do lugar institucional do governo federal produzem sentidos sobre a violência de Estado exercida no período ditatorial.
\end{abstract}

Palavras-chave: Análise do Discurso; memória; silenciamento; violência de Estado.

\begin{abstract}
This paper, associated to the theoretical perspective of the Materialist Discourse Analysis, considering especially the concepts of memory, silence, historicity, proposes a gesture of analysis of three institutional documents issued by the Ministry of Defense of the current government in the years 2019, 2020 and 2021 which consist of the Order of the Day allusive to March 31, 1964. The main objective is to understand how these official notes commemorating/remembering the 1964 coup issued from the institutional place of the federal government produce meanings about the State violence exercised in the dictatorial period.
\end{abstract}

\footnotetext{
${ }^{1}$ Doutora em Linguística pela UNICAMP (1996). Professora titular do Departamento de Ciências da Linguagem da Universidade Federal Fluminense (UFF). Docente e orientadora no Programa de Pós-Graduação em Estudos de Linguagem também da UFF. Bolsista de produtividade em pesquisa do CNPq, nível 1C.

2 Doutora em Estudos de Linguagem pela Universidade Federal Fluminense (2020). Mestra em Estudos de Linguagem (2016) pela Universidade Federal Fluminense, Especialista em Língua Portuguesa (2014) e licenciada em Letras (Português/Espanhol) também pela UFF (2012). Atualmente, é docente substituta no curso de Letras no Instituto Federal Fluminense campus Campos Centro.

3 Doutora em Estudos de Linguagem pela Universidade Federal Fluminense (2021), com sanduíche na Universidade Nova de Lisboa. Mestra em Estudos de Linguagem pela Universidade Federal Fluminense, com bolsa Capes. Especialista em Leitura e Produção Textual pela Universidade Estácio de Sá (2011) e licenciada em Letras (Português/Literatura) pela mesma Universidade (2008).
} 
Keywords: Discourse analysis; memory; silence; State violence.

\begin{abstract}
"Oppressive language does more than represent violence; it is violence; does more than represent the limits of knowledge; it limits knowledge. Whether it is obscuring state language or the faux-language of mindless media; whether it is the proud but calcified language of the academy or the commodity driven language of science; whether it is the malign language of law-without-ethics, or language designed for the estrangement of minorities, hiding its racist plunder in its literary cheek - it must be rejected, altered, and exposed. It is the language that drinks blood, laps vulnerabilities, tucks its fascist boots under crinolines of respectability and patriotism as it moves relentlessly toward the bottom line and the bottomed-out mind. Sexist language, racist language, theistic language - all are typical of the policing languages of mastery, and cannot, do not permit new knowledge or encourage the mutual exchange of ideas"”.
\end{abstract}

(Toni Morrison, em discurso de agradecimento no Prêmio Nobel de Literatura, 1993).

\title{
Introdução
}

O que é a violência de Estado? Esta é uma pergunta a ser trabalhada por um analista do discurso no entremeio das Ciências Humanas e sociais, seguindo o gesto teórico inaugural proposto por Pêcheux em 1969. Nesse gesto, que se estende em outras obras publicadas nos anos seguintes, Pêcheux propõe a tarefa de construir um campo teórico não conforme às divisões positivistas do saber disciplinarizado. Campo este que conceitua o discurso como efeito de sentidos e situa seu modo de construir saber a partir da interpenetração e reterritorialização da Linguística, do Materialismo Histórico e da Psicanálise.

Tomando, neste artigo aqui proposto, a discussão sobre os modos como os sentidos estão historicamente construídos, no Brasil de hoje, em torno desses dois significantes - 'violência' e 'Estado' -, nossa posição a partir da Análise do Discurso materialista será a de compreender

\footnotetext{
${ }^{4}$ A linguagem opressiva faz mais do que representar a violência; é violência; faz mais do que representar os limites do conhecimento; limita o conhecimento. Se está obscurecendo a linguagem estatal ou a linguagem falsa da mídia insensata; se é a linguagem orgulhosa, mas calcificada, da academia ou a linguagem orientada pela mercadoria da ciência; seja a linguagem maligna da lei sem ética, ou a linguagem destinada ao estranhamento das minorias, escondendo sua pilhagem racista em sua face literária - ela deve ser rejeitada, alterada e exposta. É a linguagem que bebe sangue, enverga vulnerabilidades, coloca suas botas fascistas sob crinolinas de respeitabilidade e patriotismo enquanto se move incansavelmente em direção à linha de fundo e à mente de baixo. Linguagem sexista, linguagem racista, linguagem teísta — todos são típicos das linguagens policiais de domínio, e não podem, não permitem novos conhecimentos ou incentivam a troca mútua de ideias. (Tradução de Ricardo Moura: https://medium.com/textura/toni-morrison-e-a-for\%C3\%A7a-da-linguagem-6b154479a4aa. Acesso em 21 de abril de 2021).
} 
os modos linguageiros de produção da violência do Estado, tendo em vista determinados acontecimentos em dadas condições de produção. Como são formulados os discursos que sustentam ou justificam a violência por parte do Estado? Considerando, pois, o funcionamento das discursividades que engendram e justificam processos violentos contra a sociedade, o artigo que escrevemos a seis mãos tem como proposta analisar enunciados que circulam institucionalmente legitimando discursos sobre a tortura/ditadura em períodos democráticos, ou seja, em condições de produção bastante específicas.

Desse modo, em termos centrais, nosso corpus é composto por três documentos institucionais emitidos pelo Ministério da Defesa do atual Governo Federal nos anos de 2019, 2020 e 2021, que apresentam a Ordem do Dia Alusiva ao 31 de Março de 19645. As três declarações, assinadas e autorizadas pelo respectivo Ministro da Defesa, à época, foram lidas em todos os quartéis e instalações militares brasileiras, em data que marca o dia do golpe militar, como é de praxe, como uma forma de comemoração ao evento.

Em tais documentos institucionais, o encontro da linguagem com a história engendra processos de produção de sentidos nessa discursividade política brasileira recente. São enunciados que vão de afirmativas saudosas sobre a ditadura militar à conclamação ao golpe, com elogio à atuação das Forças Armadas na época da ditadura militar. É importante discernir a discursividade em torno do uso efetivo da violência, como forma de repressão em estados democráticos, do rememorar positivamente o uso da violência em períodos autoritários. Há enunciados que justificam os excessos repressivos violentos como forma de garantir a paz em uma democracia. E há, também, a circulação de enunciados que enaltecem a violação sistemática dos Direitos Humanos durante a ditadura. Nos dois casos, a violência é significada e justificada como defesa de $\mathrm{X}$, sendo $\mathrm{X}$ muitas vezes dito em torno da defesa dos "homens de bem". Mas como são significados esses "homens de bem" em nome dos quais a violência é expressamente desejada? Vejamos.

Em artigo recente, Mariani (2019) discutiu o modo como muitas democracias justificam a violência como meio de dar garantias aos cidadãos. Os excessos policiais com uso de bombas de efeito moral, balas de borracha e espancamentos, seja na repressão a um assalto ou na dispersão de uma manifestação popular, por exemplo, são empregados e justificados em defesa da democracia. Nessa perspectiva, a democracia aparece associada à paz, ao interesse público,

\footnotetext{
${ }^{5}$ Disponível em: https://www.gov.br/defesa/ptbr/@@search?SearchableText=Ordem+do+Dia+Alusiva+ao+31+de+Mar\%C3\%A7o+de+1964 - Acesso em 21 de abril de 2021.
} 
aos direitos do ir-e-vir pelas cidades. A violência é empregada, portanto, em nome da paz e dos direitos... certamente de alguns.

No contexto político democrático, a expressão weberiana 'violência legítima' representa justamente uma inversão de sentido no modo como usualmente se significa violência. A expressão "violência legítima" é significada como forma de ação "em nome de todos, em defesa do patrimônio, do território, ou a fim de assegurar a vida pacífica, essa violência contaria com o apoio da sociedade.” (MARIANI, 2019, p. 279). Segundo Weber,

\footnotetext{
Precisamente hoje, a ligação do Estado com a violência é particularmente íntima. (...) No passado, as mais diversas associações - começando pelo clã - conheceram a violência física como uma coisa completamente normal. (...) Pois, o específico do presente é o fato de só se atribuir a todas as outras associações ou pessoas particulares o direito à violência na medida em que o Estado as admite como estando do seu lado: ele [o Estado] é considerado como a fonte única do direito à violência (WEBER, 2015 [1919], p. 62-63, apud MARIANI, 2019, p. 279).
}

De uma posição discursiva democrática, dizer "violência legítima" é autorizar a violência de Estado em mais de um contexto, ou seja, indistinguindo os acontecimentos. É nessa medida que a disputa pelo direito de comemorar o golpe militar, reautorizada por uma decisão do TRF-5, em março de 2021, ganha relevância, ao dar a ver/ler ("nova") tentativa de reescritura da história brasileira, no que diz respeito ao período ditatorial iniciado em 31 de março de 1964.

É importante destacar, em relação às condições de produção do corpus em análise, que as práticas discursivas e não discursivas de comemoração do golpe de 1964 não se inauguram no atual governo, isto é, possuem uma anterioridade digna de ser ressaltada. Teixeirense (2019) analisa a questão tomando como base a postura de todos os presidentes da República pósditadura, desde José Sarney até o atual governo. Destaca-se, em sua análise, o fato de que a comemoração ao golpe se manteve, até então, como iniciativa das Forças Armadas Brasileiras. Como afirma o historiador, “é a primeira vez no período democrático que um Presidente da República incentiva a celebração do golpe que originou a ditadura militar, que, entre 1964 e 1985, resultou em centenas de mortos e desaparecidos" (TEIXEIRENSE, 2019, s. p).

O autor afirma ainda que foi somente no governo de Dilma Rousseff que "o Palácio do Planalto passou a adotar nova abordagem no tocante à memória do golpe de 1964 e às graves violações de direitos humanos que deram causa os agentes do Estado" (TEIXEIRENSE, 2019, s. p.). Foi pela Lei de Acesso à Informação (Lei 12.527/2011) e pela instituição da Comissão Nacional da Verdade (Lei 12.528/2011), em 2012, que se possibilitou um aprofundamento nas discussões e a apuração das violações dos direitos humanos durante o período ditatorial. De 
acordo com o autor, foi por iniciativa da presidenta Dilma Rousseff que, naquele momento, se proibiu a celebração do golpe de 1964 nos quartéis e outras repartições do país. E essa iniciativa, que trazia medidas que buscavam a reparação às vítimas e o conhecimento sobre a violência de Estado exercida no período ditatorial, acabou por intensificar as disputas pela memória desse período, desgastando as relações entre a presidenta e as Forças Armadas. Com o golpe/impeachment de Dilma Rousseff em 2016, Michel Temer, que assumiu a presidência, retomou o "discurso enaltecedor do papel das Forças Armadas na história política do país" (TEIXEIRENSE, 2019, s. p.), o que vai se desdobrar em disputas mais recentes durante o atual Governo Federal.

Desse modo, "novas" disputas pelo direito de comemorar a data vêm sendo travadas no âmbito jurídico. Desde 2019, quando o Governo Federal orientou os quartéis a comemorar o golpe e publicou, no site do Ministério da Defesa, a Ordem do Dia Alusiva ao 31 de março de 1964, lida nos quartéis à data, pedidos de proibição foram protocolados, por diversas instâncias. Nesse mesmo período, em 29 de março de 2019, a juíza federal Evani da Luz atendeu a um pedido de liminar apresentado pela Defensoria Pública da União e proibiu a publicação da nota. A decisão, no entanto, foi derrubada, menos de 24 horas depois, pela desembargadora Maria do Carmo Cardoso, que acatou o recurso da Advocacia-Geral da União.

Em 2020, a deputada federal Natália Bonavides (PT-RN) foi responsável pela Ação Popular contra a União e o Ministro da Defesa, que resultou na "nova" proibição à comemoração do golpe. Já em 17 de março de 2021, acatando o recurso do atual Governo Federal, a $5^{\text {a }}$ Região do Tribunal Regional Federal (TRF) decidiu reautorizar as comemorações ao golpe de 1964. Essa decisão da justiça federal derruba a liminar que impedia a publicação de qualquer comemoração referente ao golpe em rádio, televisão, internet ou outro meio, o que inclui as notas, que serão aqui analisadas, publicadas em site do Governo Federal, que classificam o golpe de 1964, entre outros modos, como um "marco para a democracia brasileira" $"$

A derrubada da liminar autoriza também nova publicação da Ordem do Dia, feita em 31 de março de 2021, no mesmo site, em que o golpe é significado como um "movimento" que é "parte da trajetória histórica do Brasil", por isso, ainda segundo a nota, "devem ser compreendidos e celebrados os acontecimentos daquele 31 de março"7.

\footnotetext{
${ }^{6}$ Disponível em: https://www.gov.br/defesa/pt-br/centrais-de-conteudo/noticias/ultimas-noticias/ordem-do-diaalusiva-ao-31-de-marco-de-1965 - Acesso em 21 de abril de 2021.

${ }^{7}$ https://www.gov.br/defesa/pt-br/centrais-de-conteudo/noticias/ordem-do-dia-alusiva-ao-31-de-marco-de-1964$\underline{2021}$ - Acesso em 21 de abril de 2021.
} 
Com isso, podemos afirmar que a posição adotada pelo atual Governo Federal não apenas reautoriza, como também incentiva a comemoração ao golpe, o fazendo a partir do lugar institucional de chefe de Estado, deslocando a Ordem do Dia Alusiva ao 31 de março de 1964 do âmbito da chefia das Forças Armadas para o âmbito do Ministério da Defesa, órgão do Governo Federal responsável por dirigir essas instâncias, produzindo efeitos no jogo de forças e de sentidos. Desse modo, algumas perguntas se fazem necessárias e direcionam o presente trabalho: De que modo essas notas oficiais de comemoração/rememoração do golpe de 1964 emitidas do lugar institucional do Governo Federal produzem sentidos sobre a violência de Estado exercida no período ditatorial? Que deslocamentos se produzem nos modos de se significar a ditadura militar? Como a tortura e os assassinatos praticados nesse período são significados, nesses documentos oficiais?

\title{
1 Memória, silêncio, historicidade
}

\begin{abstract}
"A certeza que aparece [...] é que uma memória não poderia ser concebida como uma esfera plena, cujas bordas seriam transcendentais históricos e cujo conteúdo seria um sentido homogêneo, acumulado ao modo de um reservatório: é necessariamente um espaço móvel de divisões, de disjunções, de deslocamentos e de retomadas, de conflitos de regularização... Um espaço de desdobramentos, réplicas, polêmicas e contra-discursos".
\end{abstract}

(Michel Pêcheux, em Papel da Memória, 2015 [1983]).

No âmbito da teoria na qual nos inscrevemos, a Análise do Discurso materialista, consideramos os três documentos como texto; conforme destaca Orlandi (1995, p. 112), “o texto, visto na perspectiva do discurso, não é uma unidade fechada [...] pois ele tem relação com outros textos (existentes, possíveis ou imaginários), com suas condições de produção (os sujeitos e a situação), com o que chamamos sua exterioridade constitutiva (o interdiscurso)". Do nosso ponto de vista, o texto é compreendido em sua discursividade, pois na base material da língua inscrevem-se os acontecimentos históricos, as disputas pelos sentidos e as posições sujeito que sustentam essas disputas. Além disso, estabelece com a história uma relação constitutiva da produção de sentidos. É o que chamamos, junto a Orlandi (ibidem, p. 113), de historicidade. Mariani (1999, p. 47), a esse respeito, acrescenta que "um trabalho de análise que tome como objeto os discursos institucionais precisa considerar a historicidade do processo 
de constituição da própria instituição, ou seja, o modo como a instituição, ao se constituir como tal, discursivizou-se".

Compreendemos, assim, que os textos produzem sentidos de um modo e não de outro; o que se dá a ler/ver, nas discursividades aqui trazidas à análise, é uma trama de sentidos, um tecido, a partir do qual nos interessa questionar o como mais do que o quê. Destacamos, ademais, que a mudança de postura adotada pelo atual governo, ao deslocar as Ordens do Dia Alusivas ao 31 de março de 1964 para o site do Ministério da Defesa, produzem um deslocamento de posição enunciativa, o que nos permite afirmar, ainda junto a Mariani (1999, p. 49), que as fronteiras da produção de sentidos para presidência da República, enquanto instituição, são sempre móveis.

Ao produzirmos um gesto de leitura dos três documentos de Ordem do Dia Alusiva ao 31 de março de 1964 publicados no site do Ministério da Defesa, respectivamente em 2019, 2020 e 2021, observamos um processo de repetibilidade: os três produzem uma narrativa da história do Brasil, com ênfase nos eventos que culminaram na tomada de poder pelos militares, em 1964. Os três se configuram como um gesto de interpretação comemorativo ao 31 de março de 1964 que produz evidências ao mesmo tempo em que estabelece uma política de silenciamento sobre a violência cometida. Como afirma Robin (2016, p. 19, grifo nosso), “quando não é diretamente uma 'questão de memória', é a comemoração que vem em primeiro plano na atualidade, o patrimônio, as ‘Jornadas do patrimônio', todas as formas de museificação do passado. O passado vem nos visitar permanentemente".

Para Courtine (2014[1981], p. 239), os rituais verbais de comemoração produzem um recorte no tempo e, assim, ligam "o tempo da enunciação ao domínio de memória em uma anulação imaginária do processo histórico, em sua duração e suas contradições”. E essa relação imaginária com o tempo se estabelece no recorte temporal do calendário, na comemoração de um aniversário: "nesse efeito de memória particular instaurado pela repetição de um momento primeiro, no interior de um discurso cujos dias estão contados" (COURTINE, 2014 [1981], p. 239).

Discursivamente, compreendemos, portanto, que toda revisitação ao passado produz movimentos no campo dos sentidos, nos modos de se compreender o próprio passado, o presente e o futuro, atualizando sentidos e silenciando (ORLANDI, 2015 [1990]) outros no processo de significação. Isto porque, de acordo com Robin (2016, p. 31), “o passado não é livre. Nenhuma sociedade o deixa à mercê da própria sorte. Ele é regido, gerido, preservado, explicado, contado, comemorado ou odiado. Quer seja celebrado ou ocultado, permanece uma 
questão fundamental do presente". Há, portanto, um gerenciamento de memória. Ao se produzir uma narrativa de rememoração do acontecimento que deve ser celebrado em data específica, silenciam-se sentidos outros, indesejáveis, institucionalizando dizeres e legitimando uma memória. Nesta perspectiva, Silva (2021, p. 256) acrescenta que "no momento em que novos acontecimentos irrompem em novas condições sócio-históricas, surgem também novas maneiras de reger a memória em consonância aos interesses que ora se apresentam”.

De acordo com Mariani (1998, p. 106-107), há um fio de narratividade que trabalha junto à memória discursiva institucionalizando dizeres possíveis em determinadas condições de produção. Esse fio de narratividade, diz a autora, tece e conduz "o ecoar das repetições parafrásticas, impedindo o deslizar dos significantes e/ou as resistências históricas, misturando passado, presente e futuro". Conforme afirma Orlandi (2017, p. 310), a memória funciona pela narratividade, que é, pois, crucial no processo de significação. Para a autora, a narratividade “carrega as marcas do inconsciente e da ideologia na formulação produzida pelo sujeito". Orlandi (2017, p. 309) defende ainda que é pela narratividade que se textualiza a memória, inscrevendo-a na formulação.

Assim, a partir dessas propostas teórico-metodológicas, apresentamos, a seguir, um gesto de análise de nosso corpus.

\section{0 golpe de 1964 na ordem do dia}

"O passado é isso, uma coleção de fantasmas que moram com a gente".

(Marília Garcia, em Sem saída, 2021, p. 69).

Para o gesto de análise de nosso corpus, propomos o quadro que segue em que as Sequências Discursivas (SD) recortadas correspondem às Ordens do Dia aqui analisadas (SD12019; SD2- 2020; SD3- 2021) e estão organizadas em fios condutores, conforme trabalha Silva (2021), que compõem, em nosso gesto de leitura, o fio de narratividade que perpassa os documentos institucionais em análise.

Podemos observar, em nosso gesto de análise, que os mecanismos de significação se produzem em um processo parafrástico, em que os enunciados vão se reformulando, ao longo dos três documentos. Há uma repetibilidade persistente que se institui nesses dizeres como forma de sedimentar uma memória; esta memória que se quer institucionalizar sobre o 
acontecimento de 31 de março. É preciso dizer e redizer “o mesmo", sedimentar uma memória para saturar os sentidos e não permitir outra interpretação.

Vejamos o quadro e, em seguida, as análises propostas.

\begin{tabular}{|c|c|c|c|}
\hline FIO CONDUTOR & SD1 (2019) & SD2 (2020) & SD3 (2021) \\
\hline $\begin{array}{c}\text { A } \\
\text { AMEAÇA }\end{array}$ & 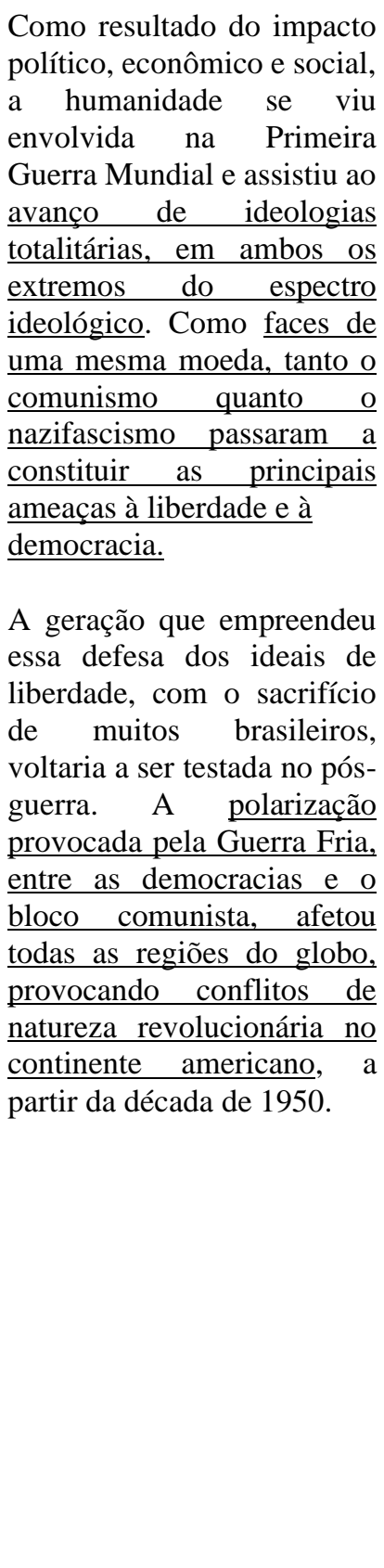 & 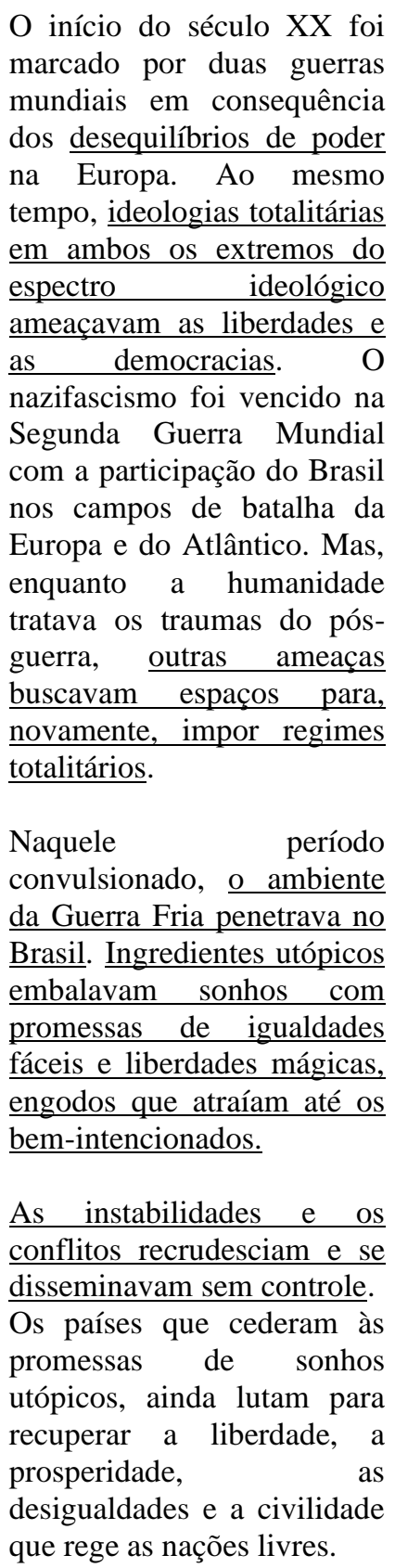 & $\begin{array}{l}\text { A Guerra Fria envolveu a } \\
\text { América Latina, trazendo } \\
\text { ao Brasil um cenário de } \\
\text { inseguranças com grave } \\
\text { instabilidade política, } \\
\text { social e econômica. } \\
\text { Havia ameaça real à paz } \\
\text { e à democracia. }\end{array}$ \\
\hline O APOIO: & $\begin{array}{l}\text { As famílias no Brasil } \\
\text { estavam alarmadas e } \\
\text { colocaram-se em marcha. } \\
\begin{array}{l}\text { Diante de um cenário de } \\
\text { graves convulsões, } \underline{\text { foi }}\end{array}\end{array}$ & $\begin{array}{l}\mathrm{O} \text { Brasil reagiu com } \\
\text { determinação às ameaças que } \\
\underline{\text { se formavam àquela época. }} \\
\text { As instituições se moveram } \\
\text { para sustentar a democracia, }\end{array}$ & $\begin{array}{l}\text { Os } \quad \text { brasileiros } \\
\text { perceberam a emergência } \\
\text { e se movimentaram nas } \\
\underline{\text { ruas, com amplo apoio da }} \\
\text { imprensa, de lideranças }\end{array}$ \\
\hline
\end{tabular}




\begin{tabular}{|c|c|c|c|}
\hline $\begin{array}{l}\text { FAMÍLIAS, } \\
\text { BRASIL, } \\
\text { INSTITUIÇÕES, } \\
\text { SOCIEDADE, } \\
\text { EMPRESÁRIOS, } \\
\text { IMPRENSA, } \\
\text { BRASILEIROS, } \\
\text { LIDERANÇAS } \\
\text { POLÍTICAS, } \\
\text { IGREJAS }\end{array}$ & $\begin{array}{l}\text { interrompida a escalada em } \\
\text { direção ao totalitarismo. }\end{array}$ & 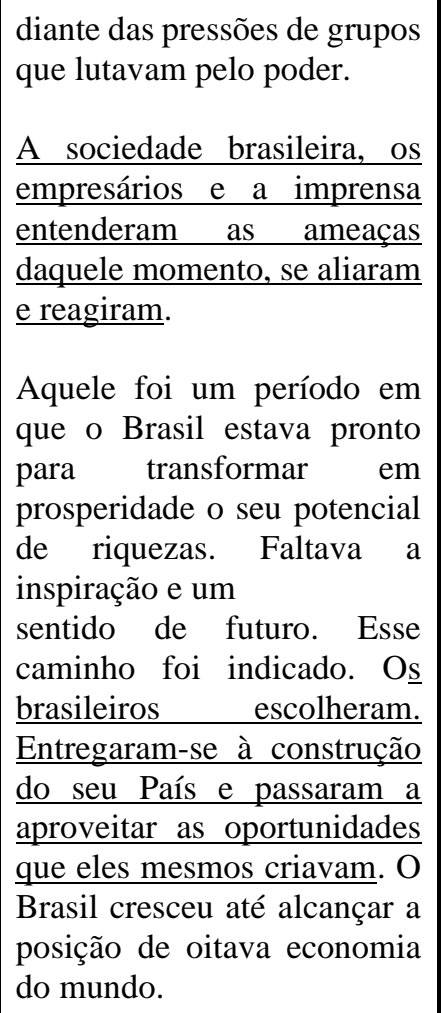 & $\begin{array}{l}\text { políticas, das igrejas, do } \\
\text { segmento empresarial, de } \\
\text { diversos setores da } \\
\text { sociedade organizada e } \\
\text { das Forças Armadas, } \\
\text { interrompendo a escalada } \\
\text { conflitiva, resultando no } \\
\text { chamado movimento de } \\
31 \text { de março de } 1964 .\end{array}$ \\
\hline $\begin{array}{c}\text { AS FORÇAS } \\
\text { ARMADAS }\end{array}$ & 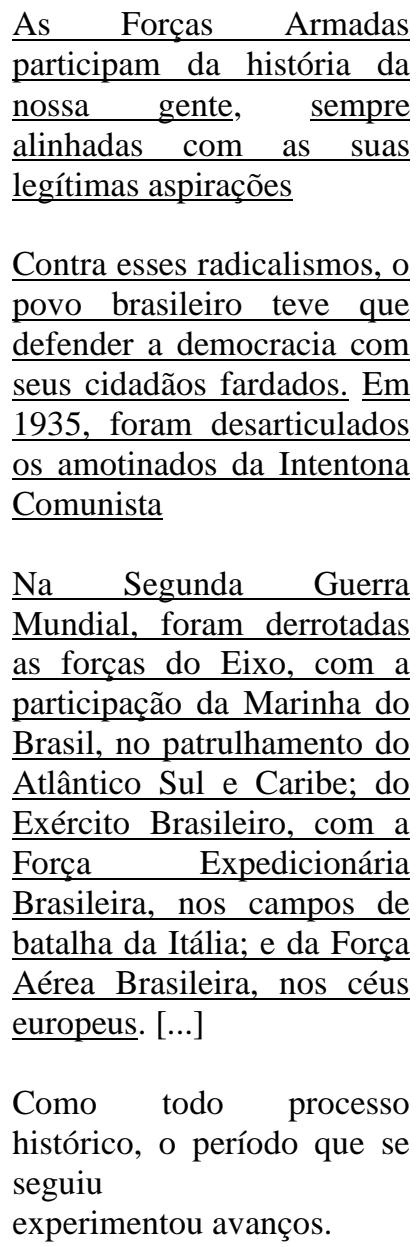 & 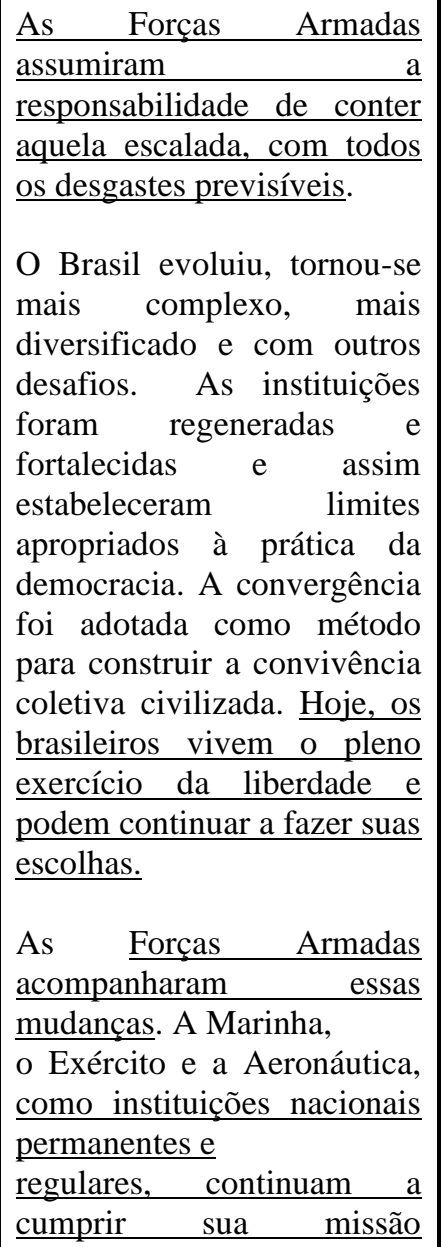 & 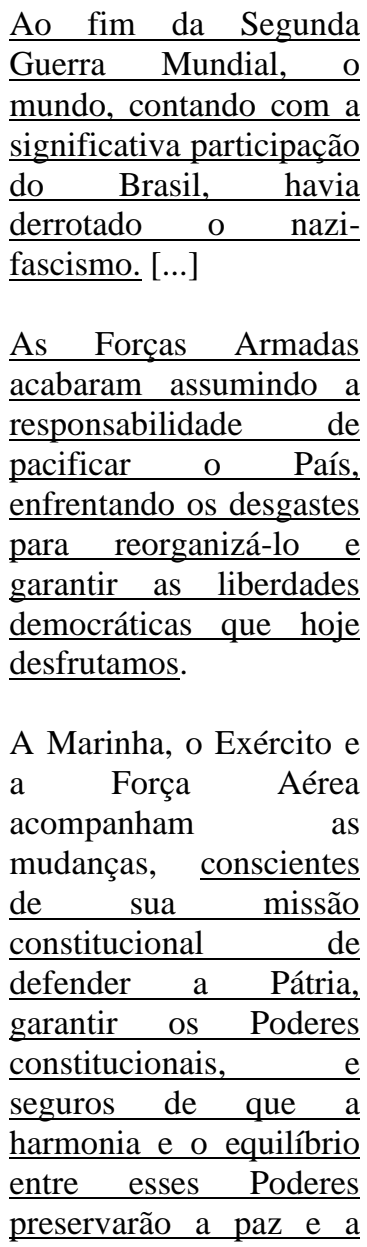 \\
\hline
\end{tabular}




\begin{tabular}{|c|c|c|c|}
\hline & 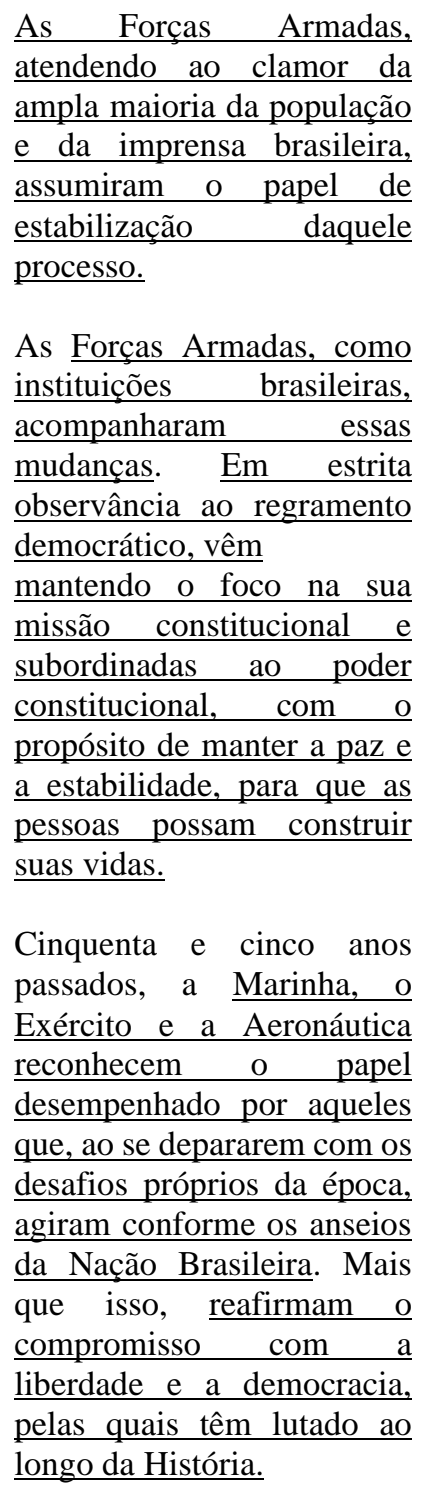 & $\begin{array}{l}\text { constitucional e estão } \\
\text { submetidas ao } \\
\text { regramento democrático com } \\
\underline{\text { o propósito de manter a paz e }} \\
\underline{\text { a estabilidade. }}\end{array}$ & $\begin{array}{l}\text { estabilidade em nosso } \\
\underline{\text { País. }}\end{array}$ \\
\hline \multirow[t]{2}{*}{$\begin{array}{l}\text { A LEI DA } \\
\text { ANISTIA }\end{array}$} & $\begin{array}{l}\text { Em 1979, um pacto de } \\
\text { pacificação foi configurado } \\
\text { na Lei da Anistia e } \\
\text { viabilizou a transição para } \\
\text { uma democracia que se } \\
\text { estabeleceu definitiva e } \\
\text { enriquecida com os } \\
\text { aprendizados daqueles } \\
\text { tempos difíceis. As lições } \\
\text { aprendidas com a História } \\
\text { foram transformadas em } \\
\text { ensinamentos para as novas } \\
\text { gerações. Como todo } \\
\text { processo histórico, o período } \\
\text { que se seguiu experimentou } \\
\text { avanços. }\end{array}$ & 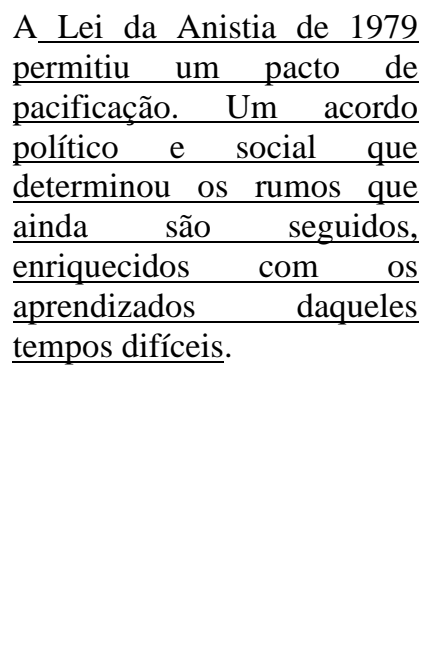 & $\begin{array}{l}\text { Em 1979, a Lei da } \\
\text { Anistia, aprovada pelo } \\
\text { Congresso Nacional, } \\
\text { consolidou um amplo } \\
\text { pacto de pacificação a } \\
\text { partir das convergências } \\
\text { próprias da democracia. } \\
\text { Foi uma transição sólida, } \\
\text { enriquecida com a } \\
\text { maturidade do } \\
\text { aprendizado coletivo. O } \\
\text { País multiplicou suas } \\
\text { capacidades e mudou de } \\
\text { estatura. }\end{array}$ \\
\hline & $\begin{array}{l}\text { O } 31 \text { de Março de } 1964 \text { foi } \\
\underline{\text { um episódio simbólico dessa }} \\
\underline{\text { identificação. }}\end{array}$ & $\begin{array}{l}\text { O Movimento de } 1964 \text { é um } \\
\underline{\text { marco para a democracia }} \\
\underline{\text { brasileira. }}\end{array}$ & $\begin{array}{l}\text { O movimento de } 1964 \text { é } \\
\text { parte da trajetória } \\
\underline{\text { histórica do } \quad \text { Brasil. }}\end{array}$ \\
\hline
\end{tabular}




\begin{tabular}{|c|c|c|c|}
\hline \multirow{4}{*}{ MARÇO } & & & Assim devem ser \\
\hline & O 31 de março de 1964 & O Movimento de 1964 é um & $\begin{array}{ll}\text { compreendidos } & \mathrm{e} \\
\text { celehrados }\end{array}$ \\
\hline & $\begin{array}{l}\text { estava inserido no ambiente } \\
\text { da Guerra Fria, que se }\end{array}$ & $\begin{array}{l}\text { marco para a democracia } \\
\text { brasileira. Muito mais pelo }\end{array}$ & $\begin{array}{lr}\text { celebrados } & \text { Os } \\
\text { acontecimentos } & \text { daquele }\end{array}$ \\
\hline & $\begin{array}{l}\text { refletia pelo mundo } \mathrm{e} \\
\text { penetrava no País. }\end{array}$ & que evitou. & $\underline{31 \text { de março. }}$. \\
\hline
\end{tabular}

Recorte das Sequências Discursivas: Ordens do Dia Alusivas ao 31 de março de 1964 - 2019- 2020- 2021

Em primeiro lugar, é possível verificar uma tentativa de contextualização do acontecimento, retomando não apenas a história do Brasil, mas um contexto mais amplo de guerras, a Segunda Guerra Mundial e a Guerra Fria, que estaria interferindo e produzindo uma ameaça ao país naquelas condições de produção. A referência às grandes Guerras que marcaram a história mundial produz um endereçamento à memória discursiva de uma guerra; de forma hegemônica, se considera que, em toda guerra, há, ao menos, dois lados em disputa, o que direciona sentidos para um mundo logicamente estabilizado, em termos de Pêcheux (1990 [1983]), em que um vence e o outro é vencido, ou seja, em que "a questão do jogo é logicamente definida como estando contida em seu resultado" (PÊCHEUX, 1990 [1983], p. 22.

É desse modo que o paralelo que se faz e se repete, nas três SDs aqui analisadas, das grandes Guerras com o período que as sucede - e que antecede o dia 31 de março de 1964 -, produz, como efeito de sentido, a pré-ditadura como um período igualmente bélico, em que, de um lado, estão os outros, aqueles contra os quais "lutamos" ("SD1: "foi interrompida a escalada em direção ao totalitarismo"); de outro, "nós", os que "lutam", as "Forças Armadas" (SD2: “As Forças Armadas assumiram a responsabilidade de conter aquela escalada"). Assim, o golpe que destituiu o presidente João Goulart e, com ele, o seu projeto de governo do poder, é silenciado, não-dito. A trama de sentidos vai, desse modo, se constituindo.

Em segundo lugar, destaca-se a referência ao apoio dado à tomada de poder pelos militares. Elencam-se, nesses enunciados, "famílias, Brasil, instituições, sociedade, empresários, imprensa, brasileiros, lideranças políticas, igrejas"; da SD1 à SD3, elementos vão sendo acrescentados, produzindo, por deslizamento, o efeito de sentido de rede de apoio, conectada, inteira, saturada, onde tudo cabe. É pela generalização que o apoio se significa. Toda rede, no entanto, se constitui de furos. Como nos diz Pêcheux (2014 [1978], p. 281), não há dominação sem que haja resistência, o que permite que haja ruptura/transformação e não uma eterna repetição da ideologia dominante.

Nessa discursividade aqui analisada, é nos furos que a resistência se inscreve, deixando ver as contradições sócio-históricas e ideológicas. No não-dito, ou melhor, no inter-dito, o que 
está silenciado comparece como margem do dizer. Como afirma Orlandi (2015, p. 31), "o silêncio não fala. O silêncio é. Ele significa. Ou melhor: no silêncio, o sentido é’’. A resistência, assim, em termos discursivos, pode ser pensada como a existência de sentido outro no silêncio. Dizemos isso porque entendemos que não se trata de um apoio por inteiro, de todas as famílias, de todos os brasileiros ou mesmo de todas as instituições. Mas ao se dizer, genericamente, do apoio desses elementos, podemos ver, neste não-dizer, o silenciamento do movimento oposto de resistência ao acontecimento do golpe e também da resistência daqueles que lutaram durante todo o regime militar e que sofreram todo tipo de violação de direitos, violência física e simbólica.

Seguindo nosso gesto de análise, podemos dizer que as Forças Armadas irrompem na trama de sentidos como participantes da história da "nossa gente" (SD1: “As Forças Armadas participam da história da nossa gente"), parte do povo brasileiro (SD1: “o povo brasileiro teve que defender a democracia com seus cidadãos fardados”), protagonista na responsabilidade de afastar o "perigo" (SD2: “As Forças Armadas assumiram a responsabilidade de conter aquela escalada, com todos os desgastes previsíveis"), trazer a "paz" (SD3: "As Forças Armadas acabaram assumindo a responsabilidade de pacificar o País, enfrentando os desgastes"), a "ordem" e a "democracia" (SD3: "para reorganizá-lo [o País] e garantir as liberdades democráticas"; "conscientes de sua missão constitucional de defender a Pátria, garantir os Poderes constitucionais, e seguros de que a harmonia e o equilíbrio entre esses Poderes preservarão a paz e a estabilidade em nosso País”).

Esse dizer de si se soma aos outros dizeres, constituindo, pela sedimentação dos sentidos, o fio narrativo que dá um sentido a esse período da história do Brasil. Nesse direcionamento de sentido, as Forças Armadas são os verdadeiros heróis, defensores da ordem, da liberdade e da democracia; estando, portanto, ao lado dos 'homens de bem'. Tudo o que foge disso, a desordem, o autoritarismo, está, mais uma vez, no campo do outro, no campo do que Duarte-Plon (2016) destaca como o "inimigo interno" a ser combatido. Segundo a autora, "o adversário a ser combatido é o inimigo interno, representado por comunistas, intelectuais, operários, camponeses, líderes sindicais, estudantes e artistas, simpatizantes de ideias consideradas subversivas" (DUARTE-PLON, 2016, p. 37). Nesses enunciados, o único vestígio de conflitos se marca em "desgastes previsíveis", “enfrentando os desgastes”. Maneira bastante eufemística de se significar toda a violência praticada pelas Forças Armadas Brasileiras contra todo aquele que ousava pensar de forma contrária ao regime. 
Ainda numa tentativa de contextualização do acontecimento, os documentos analisados fazem referência, em um salto nos acontecimentos históricos, à Lei da Anistia, de 1979. É importante dizer que a Lei da Anistia (6.683/1979), aprovada pelo Congresso e sancionada pelo presidente militar João Figueiredo, apaga os "crimes políticos" ou praticados por "motivação política" cometidos em determinado período, ou seja, liberando aqueles que eram perseguidos durante o regime militar e que sofreram as consequências de censura, repressão, tortura e até assassinatos. Conforme diz o primeiro artigo da Lei:

\begin{abstract}
Art. $1^{\circ}$ É concedida anistia a todos quantos, no período compreendido entre 02 de setembro de 1961 e 15 de agosto de 1979, cometeram crimes políticos ou conexo com estes, crimes eleitorais, aos que tiveram seus direitos políticos suspensos e aos servidores da Administração Direta e Indireta, de fundações vinculadas ao poder público, aos Servidores dos Poderes Legislativo e Judiciário, aos Militares e aos dirigentes e representantes sindicais, punidos com fundamento em Atos Institucionais e Complementares (BRASIL, 1979).
\end{abstract}

Vale ressaltar, no entanto, que esta Lei, não trouxe apenas anistia aos perseguidos políticos, mas também aos próprios militares.

Analisando as sequências discursivas, destacamos, em primeiro lugar, o apagamento das ações do próprio governo militar nesse período entre 1964 e 1979, ou seja, silencia-se tudo o que nele se produziu enquanto violência exercida pelo Estado, produzindo um efeito de que esta violência seria legítima, em nome dos 'homens de bem', logo, prevista pelas Forças Armadas. E mais, uma vez que foram anistiados, os crimes caem no esquecimento. Assim, coloca-se em destaque o fato de a Lei da Anistia ter produzido "um pacto de pacificação", como podemos ler nos três documentos. Em SD1, afirma-se que este "pacto" teria viabilizado "a transição para uma democracia que se estabeleceu definitiva e enriquecida" (SD1). Em SD2, apresenta-se também um período que produz um efeito de explicação do que teria sido este "pacto de pacificação": "Um acordo político e social que determinou os rumos que ainda são seguidos, enriquecidos com os aprendizados daqueles tempos difíceis" (SD2). E em SD3, explica-se que esta Lei foi "aprovada pelo Congresso Nacional", produzindo um efeito de legitimidade, e que teria consolidado "um amplo pacto de pacificação a partir das convergências próprias da democracia".

Além disso, ainda em SD3, formula-se o enunciado: "Foi uma transição sólida, enriquecida com a maturidade do aprendizado coletivo. O País multiplicou suas capacidades e mudou de estatura". Na referência à Lei da Anistia, uma brecha na discursividade nos dá a 
ver/ler uma contradição instaurada. Recortamos, dessas discursividades, as expressões "transição para uma democracia" e "pacto de pacificação", pondo-as em relação aos fios condutores já analisados, a saber, a ameaça, o apoio e as próprias Forças Armadas. As palavras "transição" e "pacto" apontam para uma mudança; se é a Lei da Anistia quem garante a transição para uma democracia e para a paz, o que se tinha antes era, enfim, o oposto? Não era a garantia dessas mesmas "democracia" e "paz" que legitimou, como vimos, nas discursividades analisadas, a tomada de poder pelos militares?

No último fio condutor mobilizado em nosso gesto de análise, constrói-se, discursivamente, uma imagem positiva do dia 31 de março de 1964 nas três Ordens do Dia, deixando ver, novamente, a tentativa de sedimentação de uma memória para este acontecimento.

Podemos observar, em SD1, que o dia 31 Março de 1964 é significado como "um episódio simbólico" de identificação das Forças Armadas, que possuem "legítimas aspirações", em relação ao povo brasileiro. E ainda se enuncia que este acontecimento é decorrente do "ambiente da Guerra Fria, que se refletia pelo mundo e penetrava no País", ou seja, é porque havia o ambiente de caos causado pela guerra que este acontecimento se fez necessário.

Em SD2 e em SD3, podemos ler que este acontecimento é denominado enquanto um "Movimento", ou melhor, "O Movimento de 1964" ao qual se atribui uma predicação como tentativa de saturar os sentidos em torno do dia 31 de Março de 1964. De acordo com Mariani (1998), denominar é significar. Além disso, segundo a autora, as denominações nos permitem observar as disputas, as imposições, os silenciamentos. Seguindo o trabalho de Mariani (1998), Silva (2021, p. 86) acrescenta que "a forma de denominar o acontecimento é uma forma de significá-lo, consequentemente, ressoando sentidos que se presentificarão na escrita de sua história hegemônica e sentidos que farão parte de uma história outra, que se quer e/ou se faz silenciar".

Vale ressaltar ainda que a disputa pela denominação deste acontecimento não é recente e muito menos se inaugura nestas condições de produção. Em análise dos Atos Institucionais editados pelos governos militares ao longo do período ditatorial, após o golpe de 1964, ou seja, do lugar institucional, Silva (2021, p. 100) verifica que o acontecimento de 31 de Março era denominado nesses documentos como "revolução", que, em um processo de repetibilidade, se tornou a denominação hegemônica durante o regime militar, silenciando o discurso de resistência que o denominava "golpe". Contudo, conforme destaca a autora, são as condições sócio-históricas e de poder que permitem que uma ou outra denominação se estabilize. Desse 
modo, "é o trabalho da memória, sempre no batimento com o esquecimento, que permite que a denominação golpe, marca do movimento de resistência, saia do lugar de apagamento para passar a denominar o acontecimento no interior da história, tornando-se, assim, a denominação hegemônica atual" (SILVA, 2021, p. 100). Vemos, portanto, uma nova disputa pela cristalização de sentidos em torno da denominação deste acontecimento, que nestes documentos se configura como um "Movimento".

Podemos verificar ainda que, em SD2, pela predicação atribuída ao acontecimento, constrói-se a imagem de que este "é um marco para a democracia", enunciado que se repete no mesmo documento ao que se acrescenta ainda outra afirmação: "Muito mais pelo que se evitou", apontando, portanto, para a "ameaça" à democracia que teria sido "evitada" naquelas condições de produção.

Já em SD3, a predicação atribuída ao "Movimento de 1964” caracteriza-o como aquele que "é parte da trajetória histórica do Brasil”" e, por isso mesmo, como forma de conclusão para o que se apresenta, afirma-se que "devem ser compreendidos e celebrados os acontecimentos daquele 31 de março". Para além de significar positivamente, nesta Ordem do Dia mais recente, ressalta-se, do lugar institucional que ocupa o documento, a necessidade de se "celebrar" o golpe de 1964. Assim, podemos dizer que há um processo de produção de sentidos que se marca tanto na denominação do acontecimento enquanto um "Movimento", que deixa visível a luta de força e de sentidos, quanto nos processos de predicação a ele atribuídos, saturando os sentidos e buscando impedir que outros sentidos ali se inscrevam, apagando as lutas, a resistência, produzindo silenciamentos.

É importante retomar aqui que esta celebração foi alvo de disputa judicial e autorizada a acontecer em 2021 pela $5^{\text {a }}$ região do TRF, em 17 de março de 2021. A deputada Natália Bonavides (PT-RN) respondeu, em sua rede social Twitter, na mesma data, à derrubada da liminar que impedia o Governo Federal de realizar comemorações ao golpe militar de 1964. Conforme afirma Bonavides: "INACEITÁVEL! O judiciário acaba de autorizar o governo [...] a comemorar a ditadura militar. Comemorar assassinatos, torturas e estupros? A perversidade? [...] Mais do que nunca, é hora de defender a vida, não de comemorar mortes!"”.

Em nosso gesto de leitura, essa autorização judicial produz como efeito a legitimação da violência de Estado exercida ao longo do regime militar, silenciada e justificada nos documentos institucionais aqui analisados. Há, portanto, um duplo silenciamento e uma dupla

\footnotetext{
${ }^{8}$ Disponível em: https://twitter.com/natbonavides/status/1372178357807415301 - Acesso em 28 de abril de 2021.
} 
legitimação da violência, por parte do governo de Estado que incentiva e produz institucionalmente a comemoração; e por parte da Justiça que autoriza este gesto de celebrar torturas, assassinatos e desaparecimentos. Nesta perspectiva, junto a Silva e Leite (2019) questionamos: "há o que comemorar?"; e conforme nos diz "Bonavides: Comemorar assassinatos, torturas e estupros? A perversidade?".

Vale aqui retomar Weber (2015 [1919], p. 62-63, apud Mariani, 2019, p. 279), quando afirma que a ligação do Estado com a violência é particularmente íntima. E também destacar o que defende Althusser (1980 [1976], p. 46): "o Aparelho repressivo de Estado funciona pela violência, enquanto os aparelhos ideológicos de Estado funcionam pela ideologia". Contudo, segundo Althusser, um não funciona sem o outro; o que existe é a prevalência da repressão ou da ideologia.

\title{
Considerações finais: novos velhos fantasmas nos visitam
}

\begin{abstract}
"A língua, por mais poética que possa ser, tem também uma dimensão política de criar, fixar e perpetuar relações de poder e de violência [...] No fundo, através de suas terminologias, a língua informa-nos constantemente de quem é normal e de quem é que pode representar a verdadeira condição humana".
\end{abstract}

(Grada Kilomba, em Memórias da Plantação, 2019, p. 14).

No gesto analítico empreendido neste trabalho, organizamos as Sequências Discursivas a partir de fios condutores (SILVA, 2021), compreendidos, em nosso gesto de leitura, como um fio de narratividade (MARIANI, 1998) que perpassa os documentos institucionais em análise: as três Ordens do Dia Alusivas ao 31 de março de 1964, publicadas pelo Ministério da Defesa em 2019, 2020 e 2021. A análise nos deu a ver/ler um endereçamento constante à memória da ditadura militar no Brasil, a partir de um processo de significação para a possível ameaça que teria levado os militares ao poder, às alianças que deram sustentação a essa tomada de poder, ao papel das próprias Forças Armadas nesse processo, à Lei da Anistia e ao próprio 31 de março, data marco do início da ditadura militar.

O que a análise das SDs nos mostrou é que todos esses dizeres se atravessam, se interligam. Assim, os dizeres produzidos nas três Ordens do Dia (2019, 2020 e 2021) se somam a 
outros dizeres, produzidos antes, constituindo, pela sedimentação dos sentidos, o fio narrativo que produz uma significação a esse período da história do Brasil.

Junto a Leite (2020, s/p), consideramos esse constante retorno a uma significação da ditadura militar brasileira, produzido nas Ordens do Dia aqui analisadas, como "traço de uma ferida em aberto, mas uma ferida que só dói em alguns". Como complementa a autora, "em outros, ela é significada por meio de outros jogos de linguagem, constituindo outras matrizes de sentido, que apagam os horrores, a tortura, a censura, e a significam como uma ferida "necessária', para afastar o "perigo"”.

O que se abre à leitura, nas discursividades aqui analisadas, é uma tentativa de sedimentação dos sentidos, pela repetição insistente, que impede a possibilidade de sentidos outros. Podemos observar, todavia, que, no não-dito, no inter-dito, a resistência se inscreve, dando a ver contradições sócio-históricas e ideológicas. Nos dizeres, formulados a partir do lugar institucional de um órgão do atual Governo Federal, portanto, da presidência da República, o que está silenciado comparece como margem do dizer. Junto a Orlandi (2015), reiteramos o papel do silêncio em produzir sentidos; "as palavras são cheias de sentidos a não dizer e, além disso, colocamos no silêncio muitas delas" (ORLANDI, 2015, p. 14).

O processo discursivo analisado no presente artigo também nos permite apontar a existência de uma legitimação da violência de Estado exercida no período ditatorial pelo seu silenciamento nos documentos aqui analisados. Ao se produzir, em notas oficiais, do lugar institucional da presidência, uma narrativa sobre o dia 31 de março de 1964, exaltando as ações de "heroísmo" das Forças Armadas que tomaram o poder, em 1964, e foram anistiadas em 1979, pela Lei da Anistia, silencia-se a violência e os movimentos de resistência do período.

Sugerimos, por fim, a título de considerações finais, um retorno ao ponto de partida deste artigo: a disputa pela legitimidade ou não legitimidade das Ordens do Dia Alusivas ao 31 de março de 1964 publicadas no site do Ministério da Defesa, travada, sobretudo, no âmbito jurídico. Desde março de 2019 até março de 2021, conforme descrevemos no início deste artigo, ordens judiciais fizeram com que os documentos fossem retirados do site, quando as liminares de proibição estavam em vigor, e recolocados, no instante em que o recurso da Procuradoria Geral da União era aceito e as Ordens reautorizadas. Esse movimento de ir e vir das Ordens do Dia do site governamental lembra-nos, em certa medida, a anedota do chapéu de Clémentis, de O livro do riso e do esquecimento, de Milan Kundera, narrada por Courtine (1999, p. 15-22). Enquanto aliado do dirigente comunista Klement Gottwald, Clémentis empresta seu chapéu ao líder e aparece ao seu lado em uma fotografia altamente reproduzida. Uma vez considerado 
traidor, o departamento de propaganda do governo tratou de apagá-lo das fotografias; "de Clémentis, restou apenas o chapéu de pele na cabeça de Gottwald”' (COURTINE, 1999, p. 15).

O que Courtine destaca, a respeito do estatuto da memória no campo do discurso político, é que essa tentativa de apagamento e de reescritura da história, ilustrada na anedota de Clémentis, se produz na "ordem do discurso"; “ordem do discurso das 'línguas de estado', que dividem em pedaços a lembrança dos eventos históricos, preenchidos na memória coletiva de certos enunciados, dos quais elas organizam a recorrência, enquanto consagram a outros a anulação ou a queda" (COURTINE, 1999, p. 16, grifos nossos).

É desse modo que podemos ler a disputa pela legitimidade ou não das Ordens do Dia, uma disputa que marca, de um lado e de outro, uma tentativa, instaurada na ordem do discurso, de consagrar ao outro, ao enunciado outro, ao sentido outro, a anulação ou a queda. É fundamental, todavia, destacar que, de um lado, está o silenciamento da violência, das torturas e dos assassinatos cometidos no período da ditadura militar, sendo justamente essa violência o outro a ser anulado. Enquanto, de outro, está a insistência em não se fazer esquecer essa violência; o outro a ser anulado, nesse caso, é a tentativa de apagamento da história que, a duras penas e, somente em uma democracia, se pôde (e ainda se pode) contar.

\section{Referências bibliográficas}

ALTHUSSER, L. [1976] Ideologia e Aparelhos Ideológicos de Estado. 3a. ed. Tradução de Joaquim José de Moura Ramos. Lisboa: Editora Presença, 1980.

BRASIL. Lei $N^{o}$ 6.683, de 28 de Agosto de 1979. Disponível em: http://www.planalto.gov.br/ccivil_03/leis/16683.htm

BRASIL. Ordem do Dia Alusiva ao 31 de Março de 1964. 2021. Disponível em: https://www.gov.br/defesa/pt-br/centrais-de-conteudo/noticias/ordem-do-dia-alusiva-ao-31de-marco-de-1964-2021.

BRASIL. Ordem do Dia Alusiva ao 31 de Março de 1964. 2020. Disponível em: https://www.gov.br/defesa/pt-br/centrais-de-conteudo/noticias/ultimas-noticias/ordem-do-diaalusiva-ao-31-de-marco-de-1965

BRASIL. Ordem do Dia Alusiva ao 31 de Março de 1964. 2019. Disponível em: https://www.gov.br/defesa/pt-br/centrais-de-conteudo/noticias/ultimas-noticias/ordem-do-diaalusiva-ao-31-de-marco-de-1964

COURTINE, Jean-Jacques. [1981] Análise do discurso político: o discurso comunista endereçado aos cristãos. São Carlos, SP: EDUFSCar, 2014. 
COURTINE, Jean-Jacques. O chapéu de Clémentis. In. INDURSKY, Freda; FERREIRA, Maria Cristina. Os múltiplos territórios da Análise do Discurso. Porto Alegre: Editora Sagra Luzzatto, 1999.

GARCIA, Marília. Sem saída. In. PECHANSKY, Rafaela (Org.) Partes de uma casa. Porto Alegre: TAG Experiências Literárias, 2021.

KILOMBA, Grada. Memórias da Plantação: episódios de racismo cotidiano. $1^{\mathrm{a}}$ ed. Rio de Janeiro: Cobogó, 2019.

LEITE, Milene. Sentidos de democracia: FHC e Lula no Roda Viva. Entrevista ao Alhures, 2020. Disponível em: https://www.youtube.com/watch?v=RI7 k4bMr44\&t=197s - Último acesso em 25 de abril de 2021.

MARIANI, Bethania. "Mas nessa luta se aprende. Se aprende muitíssimo!". Testemunho de resistência. Memória. In ADORNO, Guilherme; FERRAÇA, Minelly e OSTHUES, Romulo (Orgs.) O discurso nas fronteiras do social. Campinas: Pontes, 2019, p. 277-294.

MARIANI, Bethania. Discurso e instituição: a imprensa. In. Rua. Campinas, 5: 47-61, 1999.

MARIANI, Bethania. O PCB e a imprensa: os comunistas no imaginário dos jornais (19221989). $1^{a}$ edição. Rio de Janeiro: Revan e Editora da Unicamp, 1998.

ORLANDI, Eni. Análise de Discurso, alteridade, narratividade. In: Eu, Tu, Ele: discurso e real da história. $2^{\mathrm{a}}$ ed. Campinas, SP: Pontes, 2017.

ORLANDI, Eni. [1990] As formas do silêncio: no movimento dos sentidos. $4^{\mathrm{a}}$ reimpressão da $6^{\text {a }}$ edição. Campinas, SP: Editora da Unicamp, 2015.

ORLANDI, Eni. Texto e Discurso. In. Organon. Revista do Instituto de Letras da UFRGS. $1^{\text {a }}$ ed., vol. 9, 1995.

PÊCHEUX, M. [1983] O Discurso: Estrutura ou Acontecimento. Tradução Eni P. Orlandi. Campinas, SP: Pontes, 1990.

PÊCHEUX, M. Papel da Memória [1983]. In: ACHARD, Pierre [et al.]. Papel da Memória. $4^{\mathrm{a}}$ edição. Campinas, SP: Pontes Editores, 2015.

PÊCHEUX, Michel. [1975]. Semântica e discurso: uma crítica à afirmação do óbvio. $4^{\mathrm{a}}$ ed. Campinas, SP: Editora da Unicamp, 2009.

ROBIN, Régine. A memória saturada. Campinas, São Paulo: Editora da Unicamp, 2016.

SILVA, Ariana da Rosa. Dois presentes, dois passados, dois futuros: funcionamento discursivo dos votos dos deputados na sessão do impeachment de Dilma Rousseff. Tese de doutorado. Universidade Federal Fluminense, Niterói. 2021.

SILVA, Ariana.; LEITE, Milene. (2019). Democracia, ditadura, direitos humanos e a disputa de sentidos: há o que comemorar? In: DA SILVA, A.; DA SILVEIRA, C.; CAVALCANTI, M.; SALLES, S. (Orgs). Teoria e Empiria dos Direitos Humanos. Rio de Janeiro, Editora Multifoco, (p.458-474). 
TEIXEIRENSE, Pedro. Os presidentes da Nova República e a memória do golpe de 1964. In. Café com História, 1 abr. 2019. Disponível em: https://www.cafehistoria.com.br/https-wwwcafehistoria-com-br-nova-republica-ditadura-militar-golpe-de-1964/ - Último acesso em 25 de abril de 2021.

\author{
Anexos \\ MINISTÉRIO DA DEFESA \\ Ordem do Dia Alusiva ao 31 de Março de 1964 \\ Brasília, DF, 31 de março de 2019
}

As Forças Armadas participam da história da nossa gente, sempre alinhadas com as suas legítimas aspirações. O 31 de Março de 1964 foi um episódio simbólico dessa identificação, dando ensejo ao cumprimento da Constituição Federal de 1946, quando o Congresso Nacional, em 2 de abril, declarou a vacância do cargo de Presidente da República e realizou, no dia 11, a eleição indireta do Presidente Castello Branco, que tomou posse no dia 15.

Enxergar o Brasil daquela época em perspectiva histórica nos oferece a oportunidade de constatar a verdade e, principalmente, de exercitar o maior ativo humano - a capacidade de aprender.

Desde o início da formação da nacionalidade, ainda no período colonial, passando pelos processos de independência, de afirmação da soberania e de consolidação territorial, até a adoção do modelo republicano, o País vivenciou, com maior ou menor nível de conflitos, evolução civilizatória que o trouxe até o alvorecer do Século XX.

O início do século passado representou para a sociedade brasileira o despertar para os fenômenos da industrialização, da urbanização e da modernização, que haviam produzido desequilíbrios de poder, notadamente no continente europeu.

Como resultado do impacto político, econômico e social, a humanidade se viu envolvida na Primeira Guerra Mundial e assistiu ao avanço de ideologias totalitárias, em ambos os extremos do espectro ideológico. Como faces de uma mesma moeda, tanto o comunismo quanto o nazifascismo passaram a constituir as principais ameaças à liberdade e à democracia.

Contra esses radicalismos, o povo brasileiro teve que defender a democracia com seus cidadãos fardados. Em 1935, foram desarticulados os amotinados da Intentona Comunista. Na Segunda Guerra Mundial, foram derrotadas as forças do Eixo, com a participação da Marinha do Brasil, no patrulhamento do Atlântico Sul e Caribe; do Exército Brasileiro, com a Força Expedicionária Brasileira, nos campos de batalha da Itália; e da Força Aérea Brasileira, nos céus europeus.

A geração que empreendeu essa defesa dos ideais de liberdade, com o sacrifício de muitos brasileiros, voltaria a ser testada no pós-guerra. A polarização provocada pela Guerra Fria, entre as democracias e o bloco comunista, afetou todas as regiões do globo, provocando conflitos de natureza revolucionária no continente americano, a partir da década de 1950. 
O 31 de março de 1964 estava inserido no ambiente da Guerra Fria, que se refletia pelo mundo e penetrava no País. As famílias no Brasil estavam alarmadas e colocaram-se em marcha. Diante de um cenário de graves convulsões, foi interrompida a escalada em direção ao totalitarismo. As Forças Armadas, atendendo ao clamor da ampla maioria da população e da imprensa brasileira, assumiram o papel de estabilização daquele processo.

Em 1979, um pacto de pacificação foi configurado na Lei da Anistia e viabilizou a transição para uma democracia que se estabeleceu definitiva e enriquecida com os aprendizados daqueles tempos difíceis. As lições aprendidas com a História foram transformadas em ensinamentos para as novas gerações. Como todo processo histórico, o período que se seguiu experimentou avanços.

As Forças Armadas, como instituições brasileiras, acompanharam essas mudanças. Em estrita observância ao regramento democrático, vêm mantendo o foco na sua missão constitucional e subordinadas ao poder constitucional, com o propósito de manter a paz e a estabilidade, para que as pessoas possam construir suas vidas.

Cinquenta e cinco anos passados, a Marinha, o Exército e a Aeronáutica reconhecem o papel desempenhado por aqueles que, ao se depararem com os desafios próprios da época, agiram conforme os anseios da Nação Brasileira. Mais que isso, reafirmam o compromisso com a liberdade e a democracia, pelas quais têm lutado ao longo da História.

\section{FERNANDO AZEVEDO E SILVA}

Ministro de Estado da Defesa

\section{MINISTÉRIO DA DEFESA}

Ordem do Dia Alusiva ao 31 de Março de 1964

Brasília, DF, 31 de março de 2020

O Movimento de 1964 é um marco para a democracia brasileira. O Brasil reagiu com determinação às ameaças que se formavam àquela época.

$\mathrm{O}$ entendimento de fatos históricos apenas faz sentido quando apreciados no contexto em que se encontram inseridos. $\mathrm{O}$ início do século $\mathrm{XX}$ foi marcado por duas guerras mundiais em consequência dos desequilíbrios de poder na Europa. Ao mesmo tempo, ideologias totalitárias em ambos os extremos do espectro ideológico ameaçavam as liberdades e as democracias. O nazifascismo foi vencido na Segunda Guerra Mundial com a participação do Brasil nos campos de batalha da Europa e do Atlântico. Mas, enquanto a humanidade tratava os traumas do pós-guerra, outras ameaças buscavam espaços para, novamente, impor regimes totalitários.

Naquele período convulsionado, o ambiente da Guerra Fria penetrava no Brasil. Ingredientes utópicos embalavam sonhos com promessas de igualdades fáceis e liberdades mágicas, engodos que atraíam até os bem-intencionados. As instituições se moveram para sustentar a democracia, diante das pressões de grupos que lutavam pelo poder. As instabilidades e os conflitos recrudesciam e se disseminavam sem controle. 
A sociedade brasileira, os empresários e a imprensa entenderam as ameaças daquele momento, se aliaram e reagiram. As Forças Armadas assumiram a responsabilidade de conter aquela escalada, com todos os desgastes previsíveis.

Aquele foi um período em que o Brasil estava pronto para transformar em prosperidade o seu potencial de riquezas. Faltava a inspiração e um sentido de futuro. Esse caminho foi indicado. Os brasileiros escolheram. Entregaram-se à construção do seu País e passaram a aproveitar as oportunidades que eles mesmos criavam. O Brasil cresceu até alcançar a posição de oitava economia do mundo.

A Lei da Anistia de 1979 permitiu um pacto de pacificação. Um acordo político e social que determinou os rumos que ainda são seguidos, enriquecidos com os aprendizados daqueles tempos difíceis.

O Brasil evoluiu, tornou-se mais complexo, mais diversificado e com outros desafios. As instituições foram regeneradas e fortalecidas e assim estabeleceram limites apropriados à prática da democracia. A convergência foi adotada como método para construir a convivência coletiva civilizada. Hoje, os brasileiros vivem o pleno exercício da liberdade e podem continuar a fazer suas escolhas.

As Forças Armadas acompanharam essas mudanças. A Marinha, o Exército e a Aeronáutica, como instituições nacionais permanentes e regulares, continuam a cumprir sua missão constitucional e estão submetidas ao regramento democrático com o propósito de manter a paz e a estabilidade.

Os países que cederam às promessas de sonhos utópicos, ainda lutam para recuperar a liberdade, a prosperidade, as desigualdades e a civilidade que rege as nações livres.

O Movimento de 1964 é um marco para a democracia brasileira. Muito mais pelo que evitou.

\section{FERNANDO AZEVEDO E SILVA}

Ministro de Estado da Defesa

\section{ILQUES BARBOSA JUNIOR}

Almirante de Esquadra

Comandante da Marinha

Gen Ex EDSON LEAL PUJOL

Comandante do Exército

Ten Brig Ar ANTONIO C. M. BERMUDEZ

Comandante da Aeronáutica

\section{MINISTÉRIO DA DEFESA}

Ordem do Dia Alusiva ao 31 de março de 1964

Brasília, DF, 31 de março de 2021 
Eventos ocorridos há 57 anos, assim como todo acontecimento histórico, só podem ser compreendidos a partir do contexto da época.

O século XX foi marcado por dois grandes conflitos bélicos mundiais e pela expansão de ideologias totalitárias, com importantes repercussões em todos os países.

Ao fim da Segunda Guerra Mundial, o mundo, contando com a significativa participação do Brasil, havia derrotado o nazi-fascismo. O mapa geopolítico internacional foi reconfigurado e novos vetores de força disputavam espaço e influência.

A Guerra Fria envolveu a América Latina, trazendo ao Brasil um cenário de inseguranças com grave instabilidade política, social e econômica. Havia ameaça real à paz e à democracia.

Os brasileiros perceberam a emergência e se movimentaram nas ruas, com amplo apoio da imprensa, de lideranças políticas, das igrejas, do segmento empresarial, de diversos setores da sociedade organizada e das Forças Armadas, interrompendo a escalada conflitiva, resultando no chamado movimento de 31 de março de 1964.

As Forças Armadas acabaram assumindo a responsabilidade de pacificar o País, enfrentando os desgastes para reorganizá-lo e garantir as liberdades democráticas que hoje desfrutamos.

Em 1979, a Lei da Anistia, aprovada pelo Congresso Nacional, consolidou um amplo pacto de pacificação a partir das convergências próprias da democracia. Foi uma transição sólida, enriquecida com a maturidade do aprendizado coletivo. O País multiplicou suas capacidades e mudou de estatura.

O cenário geopolítico atual apresenta novos desafios, como questões ambientais, ameaças cibernéticas, segurança alimentar e pandemias. As Forças Armadas estão presentes, na linha de frente, protegendo a população.

A Marinha, o Exército e a Força Aérea acompanham as mudanças, conscientes de sua missão constitucional de defender a Pátria, garantir os Poderes constitucionais, e seguros de que a harmonia e o equilíbrio entre esses Poderes preservarão a paz e a estabilidade em nosso País.

O movimento de 1964 é parte da trajetória histórica do Brasil. Assim devem ser compreendidos e celebrados os acontecimentos daquele 31 de março.

\section{WALTER SOUZA BRAGA NETTO}

Ministro de Estado da Defesa 